\title{
Políticas de Avaliação Docente: tendências e estratégias
}

\author{
Suely da Silva Rodrigues*
}

\section{Resumo}

Em meio ao atual contexto de submissão pública dos Referenciais para o Exame Nacional de Ingresso na Carreira Docente para discussão pelo INEP/MEC, vem-se destacando a discussão acerca de políticas de avaliação docente e, consequentemente, sobre a efetividade docente. Neste sentido, este trabalho pretende apresentar algumas tendências de políticas educacionais voltadas para a melhoria da qualidade do ensino cujas estratégias envolvem a avaliação docente. Na apresentação do trabalho, destaca-se uma breve introdução ao contexto de implementação e caracterização de uma política pública de avaliação docente. A segunda parte do trabalho discute o perfil de um bom professor e a atual proposta política de seleção docente no país. A terceira parte se centra na discussão sobre algumas estratégias políticas de avaliação docente e suas possibilidades, enfatizando algumas tendências atuais acerca da utilização de indicadores educacionais para aferir a qualidade ou a efetividade docente. Palavras-chave: Política Educacional. Educação Básica. Avaliação de Professores. Efetividade Docente.

\section{Teacher Evaluation Policies: trends and strategies Abstract}

Amid the current context of public submission of benchmarks for the National Examination for Entrance into the Teaching Career for discussion by INEP / MEC, has been increasing discussion about teacher evaluation policies and thus on the effectiveness of teachers. Thus, this paper intends to present some trends of educational policies aimed at improving the quality of teaching strategies which involve the evaluation of teachers. In the presentation of work, stands a brief introduction to the context of implementation and characterization of a public policy for teacher evaluation. The second part discusses the profile of a good teacher and the current draft teaching selection policy in the country. The third part focuses on discussion of some policy strategies to evaluate teachers and their possibilities, emphasizing current trends regarding the use of educational indicators to assess the quality or effectiveness of teachers.

Keywords: Educational Policy. Elementary Education. Teacher Evaluation. Teacher Effectiveness

\footnotetext{
* Doutoranda em Educação da PUC-Rio e trabalha no Centro de Avaliação da Fundação Cesgranrio. E-mail: suely_rodrigues@yahoo.com.br
} 


\section{Políticas de evaluación docente: tendencias y estrategias Resumen}

En el actual contexto de presentación pública de los Referenciales para el Examen Nacional de Ingreso a la Carrera Docente para discusión a través del INEP/MEC (Instituto Nacional de Estudios e Investigaciones Educacionales Anísio Teixeira) ha aumentado el debate sobre las políticas de evaluación docente $y$, por lo tanto, sobre la efectividad docente. Así, este trabajo presenta algunas tendencias de políticas educacionales destinadas a mejorar la calidad de la enseñanza cuyas estrategias involucran la evaluación docente. En el presente trabajo se encuentra una breve introducción al contexto de implementación y caracterización de una política pública de evaluación docente. La segunda parte analiza el perfil de un buen profesor y la actual propuesta política de selección docente en el país. La tercera parte se centra en la discusión de algunas estrategias políticas de evaluación docente y sus posibilidades, haciendo hincapié en algunas tendencias actuales sobre el uso de indicadores educacionales para evaluar la calidad o efectividad docente.

Palabras clave: Política Educacional. Educación Primaria. Evaluación de Profesores. Efectividad docente.

\section{Apresentação}

Ao se propor a discussão da avaliação docente enquanto estratégia política para promover a qualidade de ensino pode-se refletir sobre alguns contextos que a envolvem. Mainardes (2006), analisando o ciclo de políticas delineado por Ball, coloca que é no contexto de influência que os conceitos adquirem legitimidade e formam um discurso de base para a política. Nesse contexto, em que as intenções da política estão em fase de formulação, ela sofre a influência de comissões, da mídia e, até mesmo, global ou internacional como consequência da circulação de ideias, do "empréstimo" de políticas ou, até mesmo, pelo patrocínio ou imposição de soluções por parte de agências multilaterais (OCDE, UNESCO, Banco Mundial, FMI).

As pressões da sociedade civil por uma educação de qualidade, em grande parte devido ao fraco desempenho dos alunos brasileiros nas avaliações nacionais e internacionais, além da divulgação de estudos comparativos internacionais acerca de politicas que promovem o sucesso escolar, parecem resultar na formulação e implementação de políticas públicas voltadas para o delineamento do perfil de um bom professor, para o recrutamento de profissionais que possuam tais características e monitoramento daqueles que já atuam nas redes.

Ao mesmo tempo, a proposição de estratégias de avaliação do desempenho docente enfrenta algumas oposições, principalmente por parte dos atores envolvidos nesse processo. Parte dessa resistência pode ser atribuída à diversidade de objetivos, procedimentos e efeitos que podem caracterizar 
um sistema de avaliação e, também, à diversidade de concepções de ensino, de escola e de sociedade. Dentre a variedade de finalidades de uma avaliação docente, Fernandes (2008) destaca a intenção de melhorar o desempenho dos professores; responsabilização e prestação pública de contas; melhorar práticas e procedimentos das escolas; compreender problemas de ensino e aprendizagem, contribuindo para a identificação de soluções possíveis; e compreender as experiências vividas por quem está envolvido numa dada prática social.

Ao se refletir sobre as cinco finalidades citadas, observa-se que elas se complementam e que a ideia de responsabilização é a que mais assusta aqueles que serão avaliados. Os professores justificam parte das dificuldades em promover o ensino de boa qualidade nas péssimas condições de trabalho a que são submetidos e, portanto, não querem ser responsabilizados por problemas estruturais. Assim, os medos e as dúvidas alimentam a polêmica discussão sobre os critérios e procedimentos mais adequados para cada modelo de avaliação docente.

A avaliação de professores tem o seu espaço na agenda política de muitos paises e a literatura internacional apresenta estudos que visam a captar, a partir de diversos instrumentos metodológicos, o que seria o perfil de um bom professor e qual a melhor forma de mensurar e reproduzir boas práticas docentes. Assim, por meio de uma revisão de literatura internacional baseada, principalmente, em textos publicados pelo Programa de Promoción de la Reforma Educativa de la America Latina y el Caribe (PREAL) e nos trabalhos apresentados no Seminário Internacional Avaliação de Professores na Educação Básica: uma Agenda em Discussão - promovido em 2010 pela Fundação Cesgranrio e pela Academia Brasileira de Educação, pretende-se evidenciar algumas tendências e estratégias de avaliação docente, possibilidades e obstáculos.

Além disso, considerando o momento brasileiro atual de apreensão em relação à formulação e implementação de uma política nacional de seleção de professores para o ingresso nas redes públicas de ensino, a apresentação dos resultados de alguns estudos internacionais sobre o tema poderá contribuir para a discussão pública proposta pelo governo e que substanciará o contexto de produção de texto dessa política.

Assim, a segunda parte do trabalho discute percepções do perfil de um bom professor e da atual proposta política de seleção docente no país. A terceira parte se centra na discussão sobre algumas estratégias políticas de avaliação docente, possibilidades e obstáculos, enfatizando as tendências de utilização de indicadores educacionais para aferir a qualidade ou a efetividade docente. 


\title{
Ponto de partida: concebendo o perfil de um bom professor
}

Schleicher (2006), em sua análise comparativa internacional dos sistemas escolares dos países da OCDE, resume que, em geral, as políticas dirigidas ao corpo docente partem de quatro objetivos. São eles: as preocupações relacionadas à capacidade de atração da docência como carreira profissional; ao desenvolvimento dos conhecimentos e das habilidades dos professores; à seleção, contratação e emprego dos professores; e à retenção dos professores eficazes nas instituições educacionais. Nesse trabalho ele identifica que, dentre as orientações comuns mais importantes nas políticas e práticas relacionadas ao corpo docente,

\begin{abstract}
um perfil profissional docente nítido, bem-estruturado e amplamente aceito pode converter-se em mecanismo poderoso, capaz de abranger os elementos utilizados no desenvolvimento de conhecimentos e habilidades dos professores, e de proporcionar um meio para avaliar se os programas de capacitação do corpo docente estão produzindo resultados (SCHLEICHER, 2006, p. 67).
\end{abstract}

Por sua vez, Carnoy (2009), em seu estudo comparativo entre Brasil, Chile e Cuba, sugere como solução mais simples em curto prazo para assegurar uma competência docente mínima em países como Brasil e Chile o teste do conhecimento do conteúdo e das habilidades de ensino docente depois que estes se graduam na universidade ou institutos de formação para que, dessa maneira, o Estado verifique se os professores satisfazem os níveis mínimos de conteúdo e padrões pedagógicos estipulados em seu currículo obrigatório. Segundo o autor,

0 problema no Brasil e no Chile (e na maioria dos países latino-americanos) é que não existem padrões claros do que se considera um ensino de boa qualidade e há pouca avaliação de desempenho docente mesmo entre os estudantes do magistério e dos próprios professores no início de carreira. Na maioria das profissões existe, no mínimo, medidas de resultado do trabalho. [...] Deveria também ser possivel avaliar a quantidade do trabalho docente, mesmo em termos qualitativos, se existissem padrões de desempenho claros e se os gestores fossem capazes de aplicar esses padrões de modo consistente (CARNOY, 2009, p. 201).

Assim, refletir sobre a implementação e acompanhamento de padrões de qualidade na educação torna-se uma tarefa essencial para o estabelecimento de processos de avaliação que visem à melhora do desempenho. Schleicher (2006) coloca que padrões de desempenho funcionam apenas quando implementados e avaliados de maneira uniforme e que, de maneira geral, a formulação de objetivos, padrões educacionais e a supervisão de seu cumprimento são pré-requisitos para 
elevar os níveis de desempenho. Danielson (2010) também coloca a necessidade de que educadores determinem os diferentes niveis de desempenho e um padrão para o que é um desempenho aceitável ou exemplar, ressaltando que tais padrões devem ser muito claros, sem ambigüidades, serem conhecidos e acessiveis ao público.

Em sintonia com os principais movimentos de definição de um quadro de parâmetros de avaliação dos professores no Brasil, desde 2010, discute-se uma iniciativa do INEP/MEC de se estabelecer a Prova Nacional de Concurso para o Ingresso na Carreira Docente. Segundo o site do INEP/MEC (INEP, 2010), a Prova Nacional de Concurso tem o objetivo principal de subsidiar os Estados, o Distrito Federal e os Municípios na realização de concursos públicos para a contratação de docentes para a educação básica. A prova será anualmente aplicada de forma descentralizada em todo o país para os candidatos ao ingresso na carreira docente das redes de educação básica. Caberá a cada secretaria optar pela adesão e pela forma de utilização dos resultados: se, como única prova, seguida da análise de títulos, ou, como primeira prova, seguida de uma prova adicional elaborada e aplicada pela própria secretaria.

Nesse contexto, o Brasil aguarda a validação empírica da matriz de referência da avaliação nacional para ingresso na carreira docente de professores da Educação Infantil e dos anos iniciais do Ensino Fundamental. As equipes técnicas do INEP/ MEC consultaram os padrões estabelecidos para a profissão docente na Austrália, no Canadá, em Cingapura, no Chile, em Cuba, nos Estados Unidos e na Inglaterra para levantar os fatores comuns ao perfil de um bom professor e que podem ser utilizados como critérios para avaliação da carreira docente. Como resultado, 20 fatores foram considerados recorrentes e serviram de base para a composição dos temas gerais que norteiam a elaboração da matriz de referência da Prova Nacional de Concurso para o Ingresso na Carreira Docente. No Quadro 1 a seguir apresentam-se os fatores que, segundo os estudos do INEP/MEC (INEP, 2010), são necessários a um bom professor.

Quadro 1 - Fatores selecionados pelo INEP/MEC

\begin{tabular}{|l|l|}
\hline 1. & $\begin{array}{l}\text { Domina os conteúdos curriculares das disciplinas que leciona, o que inclui a compreensão } \\
\text { de seus principios e conceitos. }\end{array}$ \\
\hline 2 & $\begin{array}{l}\text { Conhece as características de desenvolvimento dos alunos, suas experiências e contexto } \\
\text { em que vivem, e como esses fatores afetam sua aprendizagem. }\end{array}$ \\
\hline 3 & Domina a didática das disciplinas que ensina, incluindo diversas estratégias e atividades de ensino. \\
\hline 4 & Domina o currículo ou as diretrizes curriculares das disciplinas que leciona. \\
\hline 5 & $\begin{array}{l}\text { Organiza os objetivos e conteúdos de maneira coerente com o currículo, os momentos de } \\
\text { desenvolvimento dos alunos e seu nível de aprendizagem. }\end{array}$ \\
\hline 6 & $\begin{array}{l}\text { Seleciona recursos de aprendizagem de acordo com os objetivos de aprendizagem e as } \\
\text { caracteristicas de seus alunos. }\end{array}$ \\
\hline 7 & $\begin{array}{l}\text { Seleciona estratégias de avaliação coerentes com os objetivos de aprendizagem, a disciplina } \\
\text { que ensina e o currículo, permitindo que todos os alunos demonstrem o que aprenderam. }\end{array}$ \\
\hline
\end{tabular}


(continuação)

\begin{tabular}{|l|l|}
\hline 8 & $\begin{array}{l}\text { Estabelece um clima favorável para a aprendizagem, baseado em relações de respeito, } \\
\text { equidade, confiança, cooperação e entusiasmo. }\end{array}$ \\
\hline 9 & $\begin{array}{l}\text { Manifesta altas expectativas em relação às possibilidades de aprendizagem e } \\
\text { desenvolvimento de todos os seus alunos. }\end{array}$ \\
\hline 10 & $\begin{array}{l}\text { Estabelece e mantém normas de convivência em sala de aula, de modo que os alunos } \\
\text { aprendam a ter responsabilidade por sua aprendizagem e pela dos colegas. }\end{array}$ \\
\hline 11 & $\begin{array}{l}\text { Demonstra valores, atitudes e comportamentos positivos e promovem o desenvolvimento } \\
\text { deles pelos alunos. }\end{array}$ \\
\hline 12 & $\begin{array}{l}\text { Comunica-se efetivamente com os pais de alunos, atualizando-os e buscando estimular o } \\
\text { seu comprometimento com o processo de ensino-aprendizagem dos alunos. }\end{array}$ \\
\hline 13 & $\begin{array}{l}\text { Aplica estratégias de ensino desafiantes e coerentes com os objetivos de aprendizagem e } \\
\text { com os diferentes níveis de aprendizado dos alunos. }\end{array}$ \\
\hline 14 & $\begin{array}{l}\text { Utiliza métodos e procedimentos que promovem o desenvolvimento do pensamento e da } \\
\text { busca independente do conhecimento. }\end{array}$ \\
\hline 15 & $\begin{array}{l}\text { Otimiza o tempo disponivel para o ensino, garantindo o máximo de aprendizagem de cada } \\
\text { aluno durante toda a duração da aula. }\end{array}$ \\
\hline 16 & $\begin{array}{l}\text { Avalia e monitora o processo de compreensão e apropriação dos conteúdos por parte dos } \\
\text { estudantes. }\end{array}$ \\
\hline 17 & $\begin{array}{l}\text { Busca aprimorar seu trabalho constantemente a partir de diversas práticas, tais como: a } \\
\text { reflexão sistemática de sua atuação, a autoavaliação em relação ao progresso dos alunos, } \\
\text { às descobertas de pesquisas recentes sobre sua área de atuação, e às recomendações de } \\
\text { supervisores, tutores e colegas. }\end{array}$ \\
\hline 18 & $\begin{array}{l}\text { Trabalha em equipe com os demais profissionais para tomar decisões em relação à } \\
\text { construção e/ou à implementação do curriculo e de outras politicas escolares. }\end{array}$ \\
\hline 19 & $\begin{array}{l}\text { Possui informação atualizada sobre as responsabilidades de sua profissão, incluindo aquelas } \\
\text { relativas à aprendizagem e ao bem-estar dos alunos. }\end{array}$ \\
\hline 20 & \begin{tabular}{l} 
Conhece o sistema educacional e as politicas vigentes. \\
\hline
\end{tabular} \\
\hline
\end{tabular}

Fonte: INEP (2010).

Segundo os Referenciais para a Prova Nacional de Concurso para o Ingresso na Carreira Docente submetido à consulta pública, os resultados das provas proporcionarão às redes estaduais e municipais que aderirem a esse recurso de seleção docente informações importantes "sobre quais as áreas em que os professores recém contratados têm maiores conhecimentos e em quais apresentam maiores deficiências - o que poderá orientar os processos de formação continuada que cada rede realiza" (INEP, 2010, p. 5). No entanto, observa-se que muitos desses fatores não podem ser mensurados em provas escritas e, portanto, para verificar se um professor está de fato de acordo com o perfil docente delineado pelo governo federal brasileiro será necessário um processo de avaliação mais abrangente. 0 próprio INEP/MEC reconhece essa dificuldade e retirou da relação de temas gerais, presente no documento, aqueles que só poderiam ser verificados por meio da prática docente, em sala de aula. 
Constata-se, assim, que as secretarias precisarão elaborar estratégias para lidar com as deficiências diagnosticadas na própria Prova Nacional, de modo que os professores selecionados não sejam efetivados sem o necessário domínio do conteúdo e das práticas pedagógicas.

Uma solução a ser explorada é o uso devido do estágio probatório, muitas vezes marginalizado como mera formalidade e baseado apenas na assiduidade do professor.

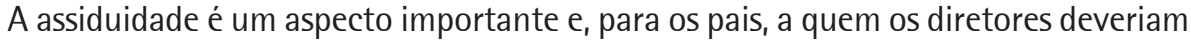
prestar contas, as faltas dos professores são sinônimo de baixa qualidade de ensino. Mas o estágio probatório poderia vir a desempenhar um papel de grande relevância como espaço para formação na prática e, como etapa constituinte do processo de seleção docente, impedir o ingresso de maus professores ou despreparados de forma definitiva na escola. Durante o estágio, seria possivel diagnosticar as dificuldades dos professores, propiciar uma chance de melhorar a prática docente e, em caso de não satisfação dos padrões exigidos, removê-los das salas de aula.

Talvez a maior dificuldade para o melhor aproveitamento do estágio probatório seja a ausência de liderança pedagógica e supervisão por parte de diretores e vice-diretores no Brasil, ao contrário do que ocorre em Cuba, por exemplo, onde, nos primeiros anos de suas carreiras, os professores são supervisionados por gestores escolares e professores orientadores (CARNOY, 2009). Segundo Carnoy, os principais efeitos da baixa qualidade dos sistemas de supervisão no Brasil, e também no Chile, são que muitos professores nunca aprendem a ensinar de modo eficaz e são incapazes de realizar um bom trabalho de ensino do currículo obrigatório, fazendo com que grande parte do conteúdo nunca seja oferecido a muitos alunos e, assim, tais alunos e seus pais nunca tomem conhecimento do quão pouco eles aprenderam em comparação ao que poderiam aprender se lhes fosse dada a oportunidade.

Além disso, a avaliação da qualidade docente não pode restringir-se ao processo de seleção. No Brasil, os professores, de maneira geral, não são sistematicamente avaliados e a promoção ocorre por tempo de serviço ou aumento na titulação, sendo assim necessário apoiá-los na melhoria de sua formação e na consolidação de uma carreira que equilibre direitos e deveres, com o estabelecimento de padrões claros que indiquem o que se espera dos professores, além de avaliações frequentes para monitorar o seu desempenho (BOLETIM DA EDUCAÇÃO NO BRASIL, 2009). Também é preciso salientar que, enquanto os salários dos professores não forem competitivos e a carreira continuar desvalorizada, será difícil atrair os melhores alunos egressos do Ensino Médio para o magistério e manter os bons professores na escola.

A seção seguinte se centrará na discussão sobre algumas estratégias políticas de avaliação docente e possibilidades e obstáculos enfrentados para a sua implementação. 


\section{Estratégias de avaliação docente: um tema controverso}

A implementação de um sistema de avaliação docente para monitorar a qualidade de ensino nas salas de aula envolve o enfrentamento de alguns desafios e, ao mesmo tempo, proporciona algumas oportunidades para todos os atores que participam do processo. Um dos principais desafios a serem superados é de natureza cultural e corresponde a uma lógica de avaliação associada à classificação, seriação e seleção e não como um processo formativo que visa à melhoria, ao desenvolvimento e às aprendizagens (FERNANDES, 2008; PERRENOUD, 1999). Outro problema está relacionado com as diferentes perspectivas desses atores acerca das finalidades da avaliação. Os professores muitas das vezes se colocam em uma posição defensiva, preocupando-se com a proteção de seus direitos, com a garantia de seus empregos, com o reconhecimento das dificuldades enfrentadas e complexidades de seu ofício, mas também anseiam por uma avaliação que os incentive a melhorar e que garantam a progressão na carreira, enquanto que os pais e administradores dos sistemas escolares se interessam pela eficácia ou efetividade docente (FERNANDES, 2008).

De acordo com Isoré (2010), alguns elementos são cruciais para superar os obstáculos enfrentados para a implementação de um sistema de avaliação do desempenho docente: (a) os professores aceitam com maior facilidade serem submetidos à avaliação quando são consultados durante a concepção do processo; (b) os professores devem saber o que se espera deles para serem reconhecidos como bons docentes e quais serão os procedimentos de avaliação antes do início do processo; e (c) a aplicação de uma implementação piloto é uma forma de garantir a viabilidade e confiabilidade do sistema antes da plena implementação e, associada às percepções dos atores chave do processo, permite a revisão do processo e a introdução de ajustes à luz de possíveis deficiências. Pode-se acrescentar a essa lista que (d) o resultado de quem está sendo avaliado deve ser o mesmo independentemente de quem seja o avaliador, de forma que um julgamento consistente feito por avaliadores treinados, especialistas do conteúdo avaliado, seja uma garantia da confiança no sistema como um todo (DANIELSON, 2010). E, também, que, (e) por ser complexo, o processo de avaliação deve exigir uma simplicidade de procedimentos, recorrendo a instrumentos ou a outras fontes de informação que se centrem exclusivamente no que é importante (FERNANDES, 2008).

Danielson (2010) diz que os sistemas de avaliação de professores abrangem três principais componentes: uma definição clara de uma boa prática pedagógica (o "o quê"), métodos justos e confiáveis para trazer à tona provas de uma boa prática pedagógica (o "como"), e avaliadores treinados que saibam 
fazer julgamentos coerentes baseados nas provas. Segundo ela, a maioria dos sistemas de avaliação de professores é baseada em critérios obsoletos e observações de aulas são conduzidas às pressas por avaliadores que não receberam treinamento e que não sabem, ao certo, o que devem observar, fazendo com que tais sistemas não sejam levados a sério nem pelos professores nem pelos administradores.

Em relação aos instrumentos de avaliação, segundo Danielson (2010), os sistemas de avaliação de professores desenvolvidos ou revisados mais recentemente apresentam como características comuns o uso de procedimentos diferenciados para professores novatos e experientes, a adoção de ciclos de avaliação periódica para professores experientes (como a cada três, quatro ou até cinco anos) e a exigência de atividades que promovam o aprendizado profissional. Isoré (2010), em sua revisão de literatura sobre avaliação docente, cita como instrumentos utilizados para avaliação as observações em aula, entrevistas, análise de portfólio preparado pelo professor, indicadores de rendimento escolar, provas, questionários e pesquisas.

Fernandes (2008) diferencia três diferentes abordagens de avaliação com diferentes focos: avaliação da qualidade dos professores focalizada na análise da competência, isto é, no sistema de saberes diversificados e específicos que eles dominam, utilizam ou em que acreditam; avaliação da qualidade do ensino focalizada na análise do desempenho dos professores e associada ao que o professor efetivamente faz como ensinar, preparar aulas, participar de reuniões e conselhos de classes; e, por fim, avaliação da eficácia dos professores focalizada na análise dos resultados dos seus alunos e, portanto, no seu efeito sobre o que os alunos são capazes de responder em determinadas situações. Intuitivamente, poder-se-ia dizer que a primeira abordagem poderia ser centrada em provas escritas, a segunda, na observação, e a terceira, na análise de indicadores de desempenho dos alunos. Assim, cada abordagem corresponde à avaliação de diferentes fontes de evidência, mais ou menos controversas, dependendo se a análise é feita sob a ótica do avaliador ou do avaliado.

Isoré (2010) resumiu em um quadro, reproduzido a seguir, os argumentos a favor e contra a avaliação docente segundo sua revisão de literatura. 
Quadro 2 - Argumentos a favor e contra a avaliação docente segundo a revisão de literatura realizada por Isoré

\begin{tabular}{|c|c|c|}
\hline & $\begin{array}{l}\text { ARGUMENTOS A FAVOR DA } \\
\text { AVALIAÇÃO DOCENTE }\end{array}$ & $\begin{array}{l}\text { ARGUMENTOS CONTRA A } \\
\text { AVALIAÇÃO DOCENTE }\end{array}$ \\
\hline \multirow{3}{*}{$\begin{array}{l}\text { Responsa- } \\
\text { bilidade pelos } \\
\text { resultados }\end{array}$} & $\begin{array}{l}0 \text { sistema atual não responsabiliza } \\
\text { os professores por sua prática } \\
\text { e desempenho. É um exercício } \\
\text { burocrático sem sentido que exige } \\
\text { mudanças. }\end{array}$ & $\begin{array}{l}\text { A concepção de um sistema de } \\
\text { avaliação justo e rigoroso para } \\
\text { efeito de responsabilização pelos } \\
\text { resultados é inútil, pois não é } \\
\text { possivel determinar o desempenho } \\
\text { de forma objetiva e o "bom ensino" } \\
\text { pode assumir diversas formas. }\end{array}$ \\
\hline & $\begin{array}{l}\text { As autoridades locais e os pais têm o } \\
\text { direito de instituir mecanismos de } \\
\text { garantia da qualidade. A revisão } \\
\text { do desempenho aumenta o apoio } \\
\text { político e público dos sistemas } \\
\text { educacionais. }\end{array}$ & $\begin{array}{l}\text { Ensinar exige um ambiente seguro, } \\
\text { longe das pressões politicas, sociais } \\
\text { e financeiras. }\end{array}$ \\
\hline & $\begin{array}{l}\text { As avaliações permitem a } \\
\text { identificação de quem tem um bom } \\
\text { desempenho de maneira similar a } \\
\text { outros mercados. }\end{array}$ & $\begin{array}{l}\text { Os mecanismos de mercado não têm } \\
\text { lugar na educação. }\end{array}$ \\
\hline \multirow[t]{2}{*}{$\begin{array}{l}\text { Mecanismos } \\
\text { de incentivo } \\
\text { e vínculos } \\
\text { com o reco- } \\
\text { nhecimento } \\
\text { e as } \\
\text { recompensas }\end{array}$} & $\begin{array}{l}\text { As avaliações fornecem uma } \\
\text { base para os incrementos da } \\
\text { remuneração que diferem } \\
\text { da escala salarial, única baseada } \\
\text { apenas na experiência. São } \\
\text { essenciais para fazer a profissão } \\
\text { mais atraente. }\end{array}$ & $\begin{array}{l}\text { Os professores não são motivados } \\
\text { por recompensas financeiras, } \\
\text { mas por aspectos intrínsecos (por } \\
\text { exemplo, o desejo de ensinar, } \\
\text { trabalhar com crianças) e condições } \\
\text { de trabalho favoráveis (horário } \\
\text { flexível, por exemplo). Alguns } \\
\text { professores podem desmotivar- } \\
\text { se como consequência dos } \\
\text { procedimentos de avaliação. }\end{array}$ \\
\hline & $\begin{array}{l}\text { Há a necessidade de adotar medidas } \\
\text { adequadas para os professores } \\
\text { ineficientes. }\end{array}$ & $\begin{array}{l}\text { É uma política paternalista que } \\
\text { estigmatiza os professores. }\end{array}$ \\
\hline $\begin{array}{l}\text { Desenvol- } \\
\text { vimento } \\
\text { profissional }\end{array}$ & $\begin{array}{l}\text { As avaliações permitem que os } \\
\text { professores identifiquem seus pontos } \\
\text { fortes e suas deficiências em relação } \\
\text { aos objectivos do estabelecimento } \\
\text { escolar e avaliem suas necessidades } \\
\text { de desenvolvimento profissional. } \\
\text { São essenciais para manter } \\
\text { os professores motivados em seu } \\
\text { trabalho. }\end{array}$ & $\begin{array}{l}\text { A seleção das atividades de } \\
\text { desenvolvimento profissional não } \\
\text { deve ser baseada em resultados das } \\
\text { avaliações, mas deve ser realizada } \\
\text { unilateralmente pelo professor. As } \\
\text { escolas não oferecem atividades } \\
\text { de desenvolvimento profissional } \\
\text { nas áreas nas quais se requer o } \\
\text { aperfeiçoamento. }\end{array}$ \\
\hline Custo & $\begin{array}{l}0 \text { sistema atual desperdiça tempo, } \\
\text { energia e dinheiro. }\end{array}$ & $\begin{array}{l}\text { Um sistema de avaliação integral } \\
\text { do professor é caro e requer muito } \\
\text { tempo. }\end{array}$ \\
\hline
\end{tabular}


(continuação)

\begin{tabular}{|l|l|l|}
\hline \multirow{3}{*}{ Efeitos } & $\begin{array}{l}\text { As avaliações melhoram a prática } \\
\text { dos professores e a aprendizagem } \\
\text { dos alunos. }\end{array}$ & $\begin{array}{l}\text { As avaliações produzem uma } \\
\text { série de efeitos negativos, tais } \\
\text { como a restrição do currículo e a } \\
\text { negligência de alguns alunos. }\end{array}$ \\
\cline { 2 - 4 } & $\begin{array}{l}\text { As avaliações de desempenho docente } \\
\text { melhoram a cooperação entre os } \\
\text { professores - por meio de debates } \\
\text { profissionais e um intercâmbio de } \\
\text { sua prática - e entre professores e } \\
\text { diretores das escolas, dos quais se } \\
\text { espera retroalimentação e coaching. }\end{array}$ & $\begin{array}{l}\text { As avaliaçes de desempenho } \\
\text { docente reduzem a cooperação } \\
\text { entre os professores - devido aos } \\
\text { efeitos da concorrência, e entre } \\
\text { professores e diretores das escola, } \\
\text { devido a relações hierárquicas ou } \\
\text { entre avaliador-avaliado. }\end{array}$ \\
\hline
\end{tabular}

Fonte: Isoré (2010, p. 22).

Muitos dos argumentos presentes no Quadro1 já foram apresentados aqui, mas cabe ressaltar que a discussão sobre o financiamento da avaliação, embora não esteja no escopo deste trabalho, é um tema que precisa ser discutido. Uma solução possível para o caso brasileiro, que possui um sistema educacional altamente descentralizado, seria a utilização dos recursos oriundos do Plano de Ações Articuladas (PAR) pelos municípios. 0 PAR prevê não só a transferência de recursos, mas também de apoio técnico do MEC para um município que apresente uma proposta de implementação de projetos que visem à melhora dos seus indicadores educacionais a partir de um roteiro de planejamento e reformas (BOLETIM DA EDUCAÇÃO NO BRASIL, 2009). Assim, pode-se vislumbrar o PAR como uma oportunidade não só de obter os recursos financeiros, mas também de conseguir a assistência técnica de que o município irá precisar para orientar o seu sistema de avaliação docente.

Segundo Fernandes (2008), dentre as possibilidades oportunizadas por um sistema de avaliação docente está claramente a de desenvolvimento profissional do professor, contribuindo para melhorar a situação pedagógica das escolas e, dessa forma, a qualidade do serviço que prestam à população. Nesse sentido, os professores terão a oportunidade de ver o seu trabalho reconhecido e valorizado, assim como os de seus colegas e o da escola em geral, propiciando um esforço coletivo que leva ao progresso e ao sucesso. Da mesma forma, também se cria a oportunidade de que os professores considerem que melhorar faz parte de suas responsabilidades como profissionais de ensino.

Em sua busca por marcos referenciais para a avaliação docente na América Latina, Vaillant (2008) cita em seu trabalho experiências implementadas em diversos países do mundo. De todas as experiências analisadas, a autora considerou que os modelos, estratégias e processos desenvolvidos para o alcance das metas de avaliação docente desenvolvidos nos Estados Unidos, Austrália, Chile e Colômbia poderiam servir de inspiração para os demais países da América Latina. 
Segundo ela, o sucesso apresentado por esses quatro paises resultam de um significativo esforço técnico que incluiu a revisão da literatura sobre o tema, a realização de seminários internacionais, a colaboração de acadêmicos nacionais e de especialistas internacionais, além da realização de experiências-piloto. Em suma, as experiências desenvolvidas nos quatro países têm permitido melhorar a compreensão da docência e proporcionar uma base sólida para a tomada de decisões, realizar um acompanhamento permanente e rigoroso dos efeitos produzidos pelos processos de mudança, e priorizar o interesse pela análise e a valorização dos resultados alcançados pelos alunos, pelos professores, pelos centros e pelo conjunto do sistema.

No caso do Chile, por exemplo, a construção do sistema de avaliação docente ocorreu no periodo de 1998 a 2005 com a participação direta do Ministério da Educação, da Associação Chilena de Municipios e do grêmio (ou sindicato) dos professores. 0 interesse dos próprios professores pelo desenvolvimento de um sistema de avaliação docente foi incentivado por um contexto em que se debatiam politicas de incentivo (bonificações) baseadas nos resultados dos alunos no Sistema Nacional de Evaluación de La Calidade de La Educación (SIMCE) e da crescente privatização da educação (ASSAÉL; PAVEZ, 2008).

No modelo chileno, os professores são avaliados a cada quatro anos por meio de portfólios, autoavaliação, entrevista e parecer do diretor da escola e do coordenador pedagógico, sendo todos os instrumentos baseados nos critérios estabelecidos no Marco para la Buena Enseñanza. De acordo com o desempenho, o professor pode ser qualificado com o nível destacado, competente, básico ou insatisfatório. Os professores considerados destacados e competentes recebem uma bonificação salarial, enquanto que os professores de nível básico ou insatisfatório recebem apoio para a melhoria de sua prática pedagógica. Os professores situados no nível insatisfatório são avaliados novamente no ano seguinte e, caso persista o resultado negativo, passam a ser acompanhados por um professor tutor. Os professores são então novamente avaliados no ano subsequente e, em caso de novo resultado insatisfatório, são obrigados a sair do sistema (ASSAÉL; PAVEZ, 2008).

Mesmo com a participação ativa dos professores na criação e desenvolvimento do sistema de avaliação chileno, ainda há espaço para desconfianças e críticas ao modelo. Uma das críticas, dentre outras, diz respeito a casos de escolas que receberam prêmio por bom desempenho possuírem, em seu efetivo, professores avaliados como insatisfatórios.

Aliás, a premiação ou o pagamento de bônus salarial são temas que estão sendo debatidos em vários paises. Outro fator que gera muitas divergências e que o determinante para o sucesso de uma política de avaliação docente é a definição dos critérios, dos métodos e das conseqüências da avaliação. Esses temas serão explorados a seguir. 


\section{Indicadores de desempenho e efetividade docente: algumas tendências}

Nos últimos anos, os sistemas educacionais brasileiros têm promovido avaliações em larga escala para medir a proficiência dos alunos, tanto na esfera nacional (SAEB/ Prova Brasil) como nas esferas estaduais e municipais (SARESP, SIADE, Prova São Paulo, etc.). Os resultados alarmantes dessas avaliações têm repercutido nas secretarias de educação e nas escolas, promovendo o debate sobre as políticas públicas e as práticas pedagógicas que poderiam ser adotadas para melhorar o desempenho dos alunos. Atualmente, alguns estados estão fazendo uso desses resultados para premiar financeiramente as escolas e/ou professores que conseguem promover o aumento das médias de proficiências de seus alunos entre os anos avaliados e isto tem gerado muita discussão, principalmente nos sindicatos dos professores, que questionam a implantação do critério meritocrático para conceder aumento salarial.

A secretaria de educação do estado de São Paulo, por exemplo, está implementando o Programa + Qualidade na Escola. A primeira etapa do programa envolveu a criação da Escola de Formação de Professores do Estado de São Paulo, adotando um curso de formação como parte do processo seletivo de docentes. A segunda etapa se basearia na valorização pelo mérito por meio do Sistema de Promoção no Quadro do Magistério, na qual as promoções significam uma evolução salarial na carreira ao longo de 5 faixas. A passagem de uma faixa para outra depende de algumas normas estabelecidas, dentre as quais está a nota obtida no Exame de Promoção de Professores (que seria realizado anualmente e cuja participação é voluntária) e a análise da vida funcional nos anos anteriores (assiduidade e tempo de permanência numa mesma escola). Vale ressaltar que diretores e supervisores também são contemplados no sistema de promoções. No $1{ }^{\circ}$ Concurso de Promoção, realizado no início de 2010, constatou-se que, dentre os professores atuantes no segundo segmento do Ensino Fundamental e/ou Ensino Médio (PEB II), compareceram 43,6\% e apenas $36,7 \%$ do contingente total da rede foram considerados aprovados (SOUZA, 2010).

Esse exemplo leva ao questionamento sobre quais estratégias devem ser adotadas para motivar a participação docente nos processos de avaliação de seu próprio desempenho, para conscientizar os professores sobre o seu nivel de desempenho atual, promover o aperfeiçoamento daqueles que estiverem abaixo do padrão desejado e valorizar aqueles que alcançam resultados positivos. Fernandes (2008) insiste na ideia de que é preciso equilibrar inteligentemente uma perspectiva de desenvolvimento profissional, mais situada e contextualizada, e uma perspectiva de responsabilização ou de prestação pública de contas, mais padronizada e centrada em medidas de desempenho ou eficácia.

O sucesso educacional da Finlândia, expresso nos resultados do Programa Internacional de Avaliação de Estudantes (PISA) - promovido pela OCDE, é frequentemente atribuído 
às políticas desse país em relação ao corpo docente, que são concebidas para garantir que pessoas competentes queiram trabalhar como professores, que o ensino seja de alta qualidade, e que todos os estudantes tenham acesso a esse ensino de excelência (SCHLEICHER, 2006). Mas o que indica a competência ou a efetividade de um professor?

Hunt (2009) entende efetividade docente como o termo usado para definir o conjunto de características, competências e condutas dos professores, em todos os niveis educativos, que levam os alunos a obter melhores resultados, incluindo objetivos específicos de aprendizagem e mais amplos, como a capacidade para resolver problemas, pensar criticamente, trabalhar colaborativamente e se tornarem cidadãos efetivos.

Para Goe (2007), os indicadores da qualidade docente podem ser definidos de diferentes formas para diferentes propósitos. No entanto, segundo a autora, a qualidade docente pode ser evidenciada em professores com as seguintes caracteristicas:

- qualificações e experiência apropriada para a matéria e o nível de ensino onde atua;

- altas expectativas para os estudantes, especialmente para os de baixo desempenho;

- criação na sala de aula, de um ambiente que encoraje a participação de todos os estudantes nas atividades de aprendizagem propostas;

- desejo de ajudar os estudantes a atingirem altos níveis de proficiências;

- habilidade de motivar os estudantes de minorias a frequentarem a escola e a participarem das atividades mesmo que eles não demonstrem alcançar ganhos significativos de aprendizagem;

- habilidade de monitorar novos professores e ação estabilizadora da permanência e coesão do corpo docente na escola; e

- disposição para trabalhar com afinco para ajudar os estudantes com necessidade de maior apoio, mesmo que os resultados do desempenho desses alunos não reflitam a contribuição do professor.

Ainda segundo Goe (2007), a medição da qualidade docente pode ser estruturada da seguinte forma: "inputs" (qualificação docente e caracteristicas do professor), processo (prática docente) e resultado (efetividade docente).

Ao apresentar a pragmática da avaliação, Perrenoud (1999, p. 53) coloca que "assim que informada à direção das escolas ou a instâncias responsáveis pelo sistema, a avaliação dos alunos permite, indiretamente, uma avaliação do estabelecimento ou dos professores". Nessa perspectiva, que constitui uma tendência de avaliação docente, seria possivel avaliar e comparar o impacto ou a efetividade dos professores por meio da avaliação externa e padronizada dos alunos.

A avaliação externa nada mais é do que avaliação e, portanto, também sofre a influência relativa aos contextos em que é realizada, tais como a intervenção do 
professor e da direção, a favor ou contra, e o nivel de comprometimento dos alunos, sem mencionar que por muitos é vista como um mero recurso de classificação de instituições de ensino.

Segundo Klein (2005), os testes de uma avaliação externa têm como finalidade aferir o conhecimento ou habilidade dos alunos em uma ou mais séries e seus resultados não se restringem a informar o percentual de acertos, mas o que os alunos sabem e são capazes de fazer através da interpretação de uma escala apropriada. Para o autor, tais diagnósticos deveriam ser utilizados em políticas públicas de melhoria da qualidade do ensino e, sendo periódicos, ter a finalidade de monitorar a qualidade de ensino por meio de uma escala apropriada e única ao longo dos anos.

Ainda segundo Klein (2005, p. 2), "as informações sobre os erros dos alunos deveriam ser utilizadas para fornecer subsídios para programas de formação e capacitação de professores".

No entanto, para Goe (2007) a medição da qualidade docente por meio do resultado dos alunos em testes padronizados ainda se configura em um desafio, pois tais testes foram concebidos para medir as proficiências dos alunos e não a qualidade do professor. Além disso, há a dificuldade de separar os efeitos do professor dos efeitos da sala de aula (clima da sala ou da escola, por exemplo) e, por fim, obter a ligação entre os dados do professor e alunos que permita conectar um professor específico ao desempenho dos alunos nos testes sem que seja feita uma pesquisa delineada com esse objetivo.

Segundo Danielson (2010, p. 6),

Usar o desempenho dos alunos para avaliar a habilidade do
professor está, em todos os casos, repleto de desafios. Os próprios
alunos variam muito em relação ao que trazem ao cenário e
alguns desses fatores estão além do alcance do professor e até
mesmo da escola. Além disso, avaliações eficazes do importante
aprendizado do aluno não estão sempre disponíveis e certamente
não para todas as áreas do currículo. Mas se forem planejados
com atenção, com as medidas adequadas de crescimento (ava-
liações antes e depois do ano escolar, por exemplo), os sistemas
podem ser justos para os professores e podem incluir informações
de importância para o ensino, isto é, para o aprendizado do aluno.

Hunt (2009) entende que a medição da efetividade docente por meio dos resultados dos alunos nas avaliações de desempenho deveria ser complementada, em todos os casos, com observações efetivas do rendimento do docente e de sua conduta em aula, na escola e na comunidade, além de outras observações da aprendizagem dos estudantes, como amostras de trabalhos ou portfólios. 
Em sua revisão de literatura, Darling-Harmond e Youngs (2002) concluem que a formação do professor é importante para as aquisições dos alunos, mas que características como a habilidade verbal e o domínio da matéria que leciona são os componentes mais importantes da efetividade docente. Além disso, os autores acrescentam que professores que terminam seus cursos de formação não estão preparados para exercerem seus cargos e que algumas qualificações docentes importam menos que as outras em função do grau e da série que o professor leciona e da matéria que ele ensina.

Em sua pesquisa sobre o desenvolvimento de métodos de valor agregado para avaliação da escola, Gray (2008) afirma que as escolas começam a refletir sobre os resultados individuais de seus alunos e que, algumas vezes, esse procedimento permite alguns pequenos avanços. Segundo ele, embora os indivíduos sejam diferentes entre si, geralmente, encontram-se boas razões para explicar o desempenho de cada um e que 0 desafio é descobrir os elementos comuns que se aplicam às experiências de todos os alunos.

Como os estudos têm comprovado que professores efetivos provocam impactos significativos na aprendizagem dos estudantes e que a efetividade varia de acordo com as caracteristicas da qualidade docente, a identificação dos componentes que o professor incorpora em sua prática docente e provoca o aumento ou a queda na aprendizagem dos alunos poderá se configurar em um valioso instrumento para auxiliar no design instrucional dos projetos de formação, capacitação e avaliação docente e com isso, resultar em medidas que promovam a eficácia escolar.

\section{Considerações Finais}

Carnoy (2009, p. 210) conclui seu trabalho dizendo que "o Estado deve garantir que todos os professores sejam eficazes na produção da aprendizagem dos alunos avaliando seu desempenho com regularidade, desde a certificação inicial até a supervisão do seu trabalho nas salas de aula". Como foi mostrado aqui, o governo brasileiro tomou a iniciativa de delinear um perfil docente para engendrar uma política de seleção que pode ser considerada um efeito das pressões advindas do contexto de divulgação dos resultados de outra política, a de avaliação de desempenho dos alunos. Mas de nada adiantará estabelecer um perfil do que se deseja se não for implementado um sistema de políticas públicas para atrair, formar e/ou capacitar candidatos a professores que correspondam a ele e, além disso, oportunizar a qualificação, valorização e avaliação do corpo docente e dos gestores educacionais que já integram os quadros públicos.

As políticas sociais e educacionais precisam atender a toda diversidade cultural, regional e socioeconômica presente no contexto brasileiro e, portanto, é preciso escutar de fato as diferentes vozes dos vários atores envolvidos no processo de avaliação.

Mesmo que se tenha boa vontade política, a possibilidade de se cometer equívocos de julgamento na determinação de procedimentos e critérios de avaliação 
existe. Portanto, nesse debate, será necessária a massiva participação de equipes pedagógicas e especializadas nos diversos conteúdos para que ao fim da discussão pública se produza um texto que corresponda a uma política justa, rigorosa e ética para com os atores envolvidos e que, de fato, vise à melhoria da qualidade do ensino.

Uma sugestão, seguindo ao que foi exposto anteriormente em meio a revisão de literatura, seria a implementação piloto do Exame Nacional de Ingresso na Carreira Docente para levantar possiveis incoerências e obter credibilidade. A mesma sugestão pode ser considerada frente à adoção de políticas descentralizadas de avaliação docente por estados e municípios. Ainda é cedo para avaliar os efeitos do programa político implementado pela Secretaria de Educação do Estado de São Paulo, no entanto, esta pode servir de exemplo e, principalmente, servir de fonte de estudos acerca de políticas de avaliação docente. Da mesma forma, pesquisas longitudinais que acompanhem os resultados dos alunos de um ou mais grupos de professores também podem reunir as condições necessárias para superar as dificuldades de uso dos resultados dos testes padronizados citadas anteriormente e subsidiar a discussão dessa prática.

Não se pode esquecer também que a avaliação só terá real significado e utilidade se as escolas e os professores estiverem verdadeiramente engajados em analisar e avaliar o trabalho que fazem e, portanto, precisam estar conscientes de todas as etapas e procedimentos envolvidos no processo, da finalidade da avaliação, dos padrões de desempenho que se espera deles, terem garantia de um julgamento imparcial e terem acesso aos seus resultados, ao que eles representam e a quais efeitos (valorativos, punitivos ou formativos) estão a ele associados.

Perrenoud (1999), por exemplo, defende a avaliação formativa e critica o caráter normativo e comparativo da avaliação tradicional, sem deixar de citar os obstáculos vivenciados na adoção de uma ou da outra lógica. Além disso, a abordagem sociológica do autor permite a reflexão sobre os contextos vivenciados pelos alunos e professores e isso facilita o entendimento das principais dificuldades enfrentadas na sala de aula e fora dela, das pressões da família, do contrato didático e do ofício do aluno, da preocupação do professor em manter sua reputação diante dos olhos do aluno e de seus colegas de trabalho e das dificuldades que ele enfrenta para romper com as práticas correntes, enfim, de toda uma lógica de avaliação, seja a serviço da seleção e da certificação, seja a serviço da regulação das aprendizagens. Esse olhar possibilita uma visão geral de duas lógicas de avaliação e das dimensões interdependentes que influenciam e, por vezes, limitam a adoção dela.

Algumas ideias interessantes podem ser captadas no trabalho desenvolvido por Ball e Bowe (1992 apud MAINARDES, 2006), tal como a de que políticas não podem ser implementadas, mas sim interpretadas e que essa transformação complexa da palavra em ação, ou de políticas em práticas, envolve um processo de atuação dos professores que varia de acordo, entre outros, com a experiência deste e das variações de contexto a que ele está submetido. Dessa forma, as políticas educacionais não são 
colocadas em prática da mesma maneira em escolas diferentes, visto que as realidades vivenciadas pela escola, em relação aos recursos humanos, financeiros ou técnicos que possui, são diferenciadas e, portanto, determinarão uma atuação ou tradução diferenciada de tais palavras (políticas) pelos professores em sala de aula (práticas).

Da mesma forma que a literatura indica que o desempenho dos alunos também está relacionado às altas expectativas de seus professores, talvez os professores possam sentir-se mais motivados e abertos a avaliação se a sociedade e os governos valorizarem a carreira docente. Por outro lado, não se pode esquecer que há muito a caminhar em termos de superação das desigualdades sociais presentes no Brasil, da formação deficiente e focada mais na teoria do que na prática docente e nas péssimas condições de trabalho.

As políticas educacionais das últimas décadas têm contribuído para que a população das camadas mais pobres tenha acesso à Educação Básica, mas estar na escola, infelizmente, não tem significado aprender. Cada vez mais se torna necessário que os professores sejam capazes de lidar com as diversidades em sala de aula, sejam elas culturais, socioeconômicas ou de níveis de conhecimento entre os alunos na área em que lecionam. Essa tarefa não é fácil, mas essencial para promover a melhoria da qualidade de ensino com equidade.

A seleção de valores morais, de conteúdos e de habilidades que melhor se encaixam em uma educação voltada para uma sociedade plural continua sendo um desafio. A formação de professores que consigam dar significado à névoa de informações que envolvem os alunos, que saibam lidar com os conhecimentos prévios deles, respeitando sua origem sociocultural se configura em grande obstáculo.

Será que a escola de hoje é capaz de superar tais desafios? De onde partiria a mudança dos centros de formação de professores e/ou profissionais de ensino ou de políticas públicas mais abrangentes? 0 Exame Nacional de Ingresso na Carreira Docente pode ser entendido como uma política pública abrangente que, dependendo da forma como for encaminhada, poderá ou não afetar os centros de formação e, principalmente, a prática docente, mas será difícil promover mudanças enquanto o problema continuar sendo o outro.

Enfim, discutir a avaliação docente envolve analisar o processo de ensino-aprendizagem e as relações entre alunos, professores, escola, governo e sociedade. Os resultados das pesquisas internacionais que analisam o impacto de ações pedagógicas ou políticas educacionais no desempenho do aluno, são de grande importância para fomentar o debate acerca da qualidade de ensino. Sendo assim, contribuem para a discussão e posterior delineamento de soluções que permitam enfrentar o desafio de superação do deficit de aprendizagem apresentado pelos alunos das redes públicas brasileiras de ensino.

Para concluir, apresenta-se a opinião do pesquisador português Domingo Fernandes $(2008$, p. 13) sobre a avaliação dos professores e seus possíveis impactos. 
A avaliação dos professores pode ser uma mera rotina burocrática e administrativa, consumidora de tempo, de esforço e de dinheiro e com pouca, ou mesmo nenhuma, utilidade para influenciar positivamente o desempenho, a competência e a eficácia dos professores e o que acontece nas escolas. Mas também pode ser, pelo contrário, um poderoso processo ao serviço da melhoria da qualidade pedagógica e da qualidade de ensino dos professores, gerando ambientes propícios à inovação, ao desenvolvimento profissional $\mathrm{e}_{1}$ consequentemente, à melhoria das aprendizagens dos alunos.

\section{Referências}

ASSAÉL, J.; PAVEZ, J. La Construcción e Implementación del Sistema de Evaluación del Desempeño Docente Chileno: principales tensiones y desafíos. Revista Iberoamericana de Evaluación Educativa, v. 1, n. 2, p. 41-55, 2008.

BOLETIM DA EDUCAÇÃO NO BRASIL. Saindo da inércia?[S.I.]: PREAL: Fundação Lemann, 2009.

BOWE, R.; BALL, S.; GOLD, A. Reforming education \& changing schools: case studies in policy sociology. London: Routledge, 1992.

CARNOY, M. A vantagem acadêmica de Cuba: por que seus alunos vão melhor na escola. São Paulo: Ediouro, 2009.

DANIELSON, C. Novas tendências na avaliação do professor. In: SEMINÁRIO INTERNACIONAL AVALIAÇÃO DE PROFESSORES DA EDUCAÇÃO BÁSICA: uma agenda em discussão, 2010, Rio de Janeiro. Anais... Rio de Janeiro: [s.n.], 2010. Disponivel em: <http://www.cesgranrio. org.br/eventos/concursos/seminario/pdf/Artigo\%20-020Charlotte \%20Danielson\%20-020 Seminario\%20Internacional\%20-020Maio\%202010.pdf>. Acesso em: 01 nov. 2010.

DARLING-HAMMOND, L; YOUNGS, P. Defining "highly qualified teachers": what does "scientifically-based research" actually tell us? Educational Researcher, v. 31, n. 9, p. 1325, 2002.

FERNANDES, D. Avaliação do desempenho docente: desafios, problemas e oportunidades. Lisboa: Texto Editores, 2008.

GOE, L. The link between teacher quality and students outcomes: a research synthesis. Washington, DC: National Comprehensive Center for Teacher Quality, 2007.

GRAY, J. Desenvolvendo métodos de valor agregado para avaliação da Escola: as experiências de três autoridades educacionais locais. In: BROOKE, N.; SOARES, J. F. (Org). Pesquisa em eficácia escolar: origem e trajetórias. Belo Horizonte: Editora UFMG, 2008. P. 252-260. 
HUNT, B. Efectividad del desenpeño docente: una reseña de la literatura internacional y su relevância para mejorar la educación em America Latina. Santiago: PREAL, 2009. (PREAL documentos, n. 43). Disponivel em: <http://www. preal.org/BibliotecaN.asp?ld_Carpeta $=64$ \&Camino=63|PrealPublicaciones/64|PRE AL Documentos>. Acesso em 01 nov. 2010.

INEP. Referenciais para o Exame Nacional de Ingresso na Carreira Docente. Disponivel em: <http://consultaexamedocente.inep.gov.br/publico/download/ Referenciais_para_o_Exame_Nacional_de_Ingresso_na_Carreira_Docente.pdf>. Acesso em: 01 nov. 2010.

ISORÉ, M. Evaluación docente: prácticas vigentes em los paises de La OCDE y uma revisión de la literatura. Santiago: PREAL, 2010. (PREAL documentos, n. 46). Disponivel em: $<$ http://www.preal.org/ BibliotecaN.asp?ld_Carpeta $=64 \&$ Camino= 63|PrealPublicaciones/64|PREAL Documentos >. Acesso em 01 nov. 2010.

KLEIN, R. Testes de rendimento escolar. In: SOUZA, A. M. (Org). Dimensões da avaliação educacional. Petrópolis, RJ: Vozes, 2005.

MAINARDES, J. Abordagem do ciclo de políticas: uma contribuição para a análise de Políticas Educacionais. Educação e Sociedade, Campinas, v. 27, n. 94, p. 47-69, jan./abr. 2006.

PERRENOUD, P. Avaliação entre duas lógicas: da excelência à regulação das aprendizagens. Porto Alegre: ArtMed, 1999.

SCHELEICHER, A. A melhoria da qualidade e da equidade na educação: desafios e respostas políticas. São Paulo: Moderna, 2006.

SOUZA, P. R. Educação de Qualidade: a política educacional de São Paulo 2006 - 2010. In: SEMINÁRIO INTERNACIONAL AVALIAÇÃO DE PROFESSORES DA EDUCAÇÃO BÁSICA: uma agenda em discussão, 2010, Rio de Janeiro. Anais... Rio de Janeiro: [s.n.], 2010. Disponivel em: < http://www.cesgranrio.org.br/eventos/ concursos/ seminario/pdf/Slides\%20-\%20Paulo\%20Renato\%20de\%20Souza\%20 -\%20Seminario\%20 Internacional\%20-\%20Maio\%202010.pdf >. Acesso em: 01 de nov. 2010.

VAILLANT, D. Algunos marcos referenciales en la evaluación del desempeño docente. Revista Iberoamericana de Evaluación Educativa, v. 1, n. 2, p. 7-22, 2008.

Recebido em: 16/03/2011

Aceito para publicação em: 04/10/2012 